\title{
A case of twitching on the pacemaker pocket
}

\author{
Belma Kalayc1 ${ }^{\mathrm{a}, *}$, Süleyman Kalayc1 ${ }^{\mathrm{b}}$, Tunahan Akgün ${ }^{\mathrm{a}}$, Turgut Karabag ${ }^{\mathrm{a}}$ \\ a Bulent Ecevit University, Faculty of Medicine, Department of Cardiology, Zonguldak 67600, Turkey \\ b Zonguldak Atatürk State Hospital, Department of Cardiology, Zonguldak, Turkey
}

\section{A R T I C L E I N F O}

\section{Article history:}

Received 12 June 2017

Received in revised form 29 June 2017

Accepted 30 June 2017

Available online 2 July 2017

\section{Keywords:}

Insulation defect

Twitching

Pacemaker

\begin{abstract}
A B S T R A C T
Pacemaker-induced extracardiac stimulation may involve the diaphragm, the pectoral or the intercostal muscles. The common causes are unipolar lead, electrode insulation defects, lead displacement and connector problems. We reported a case of twitching on the pacemaker pocket and discussed the reasons of pacemaker pocket stimulation. After evaluation of the patient we detected an insulation defect on the pacemaker lead that the cause of stimulation on pacemaker pocket.

(C) 2016 The Society of Cardiovascular Academy. Production and hosting by Elsevier B.V. This is an open access article
\end{abstract} under the CC BY-NC-ND license (http://creativecommons.org/licenses/by-nc-nd/4.0/).

\section{Case report}

A 73 year old man admitted to our hospital with pain and twitching on the pacemaker pocket. His past medical history included hypertension and right pneumonectomy due to lung cancer. The patient had a VDD pacemaker on the left side, which was implanted 9 years ago due to third degree atrioventricular block. The battery had replaced one year ago due to battery depletion. The cause after pacemaker replacement had uneventful. He felt twitching on the pacemaker pocket last night. The admission electrocardiogram revealed left bundle branch block, exaggerated pacemaker spikes in all leads with sinusal p wave (Fig. 1). His physical examination was unremarkable except rhythmic contraction of the left pectoral muscle. There was no stimulation on another part of his body including diaphragm. The blood pressure was normal, 120/75 mm Hg. The chest radiogram was as shown in Fig. 2. We evaluated him with device interrogation. Electrical measurements revealed a ventricular lead amplitude of $5.0 \mathrm{~V}$, sensitivity $2.80 \mathrm{mV}$ and an impedance of $242 \Omega$. The threshold of ventricular stimulation was $1.6 \mathrm{~V}$ at $0.40 \mathrm{~ms}$. The generator of the pacemaker was unipolar. Besides the pacemaker was on VDD mode with ventricular bipolar lead while atrial parameters were stable. The cumulative ventricular pacing was $98 \%$. We can say the ventricular lead impedance was decreased (a fall in lead impedance by more than $250 \Omega$ ). While pulse amplitude is usually remained as $5.0 \mathrm{~V}$ at the time of the pacemaker implantation. In generally the pulse amplitude is decreased after threshold test for pacemaker longevity. In this case the pulse amplitude was remained as $5.0 \mathrm{~V}$. However the main problem was not the high pulse amplitude. We

\footnotetext{
* Corresponding author.

E-mail addresses: drbelma@hotmail.com, belmauygur@gmail.com (B. Kalaycı). Peer review under responsibility of The Society of Cardiovascular Academy.
}

reduced the pulse amplitude to $3.0 \mathrm{~V}$ in order to reduce muscle stimulation. After that pectoral muscle stimulation finished instantly. However he was suffering again with twitching on pacemaker pocket in the same evening. The reasons of twitching on the pacemaker pockets were decreased impedance of ventricular lead and the unipolar polarity of the generator. We planned to replace of the ventricular lead. But he refused it because of the risks of complication and decreased lung capacity.

\section{Discussion}

Pacemaker-induced extracardiac stimulation normally involves the diaphragm, the pectoral or the intercostal muscles. ${ }^{1}$ The usual causes are positioning of the anode directly on the muscle of a unipolar pacemaker with muscle surrounding the pocket, electrode insulation defects and electrode displacement, defective coating of the pacemaker connector problems. ${ }^{2}$ If stimulation is on the diaphragm the reason may be about increased lead amplitude. In the present case the pacemaker had unipolar polarity of the generator and decreased impedance of the lead. In this way the pectoral muscle surrounding the pocket was stimulated. Pulse amplitude is usually adjusted as $5.0 \mathrm{~V}$ at the time of the pacemaker implantation. But the pulse amplitude must be decreased while threshold test was done. It is more important for pacemaker longevity and pacemaker-induced extracardiac stimulation. On chest radiogram we can see double layer appearance in the lead in pectoralis and subclavian region that is normal for a VDD pacemaker which one of them is atrial sense wire and the other one is ventricular sense and pace wire. The double layer appearance is also seen in some parts of the subclavian vein and vena cava superior which disappears after atrial sense poles. We didn't see the insulation defect on the lead in chest radiogram. Insulation defect was reported that the most common cause of lead failure; insulation defect (32\%), followed lead fracture 


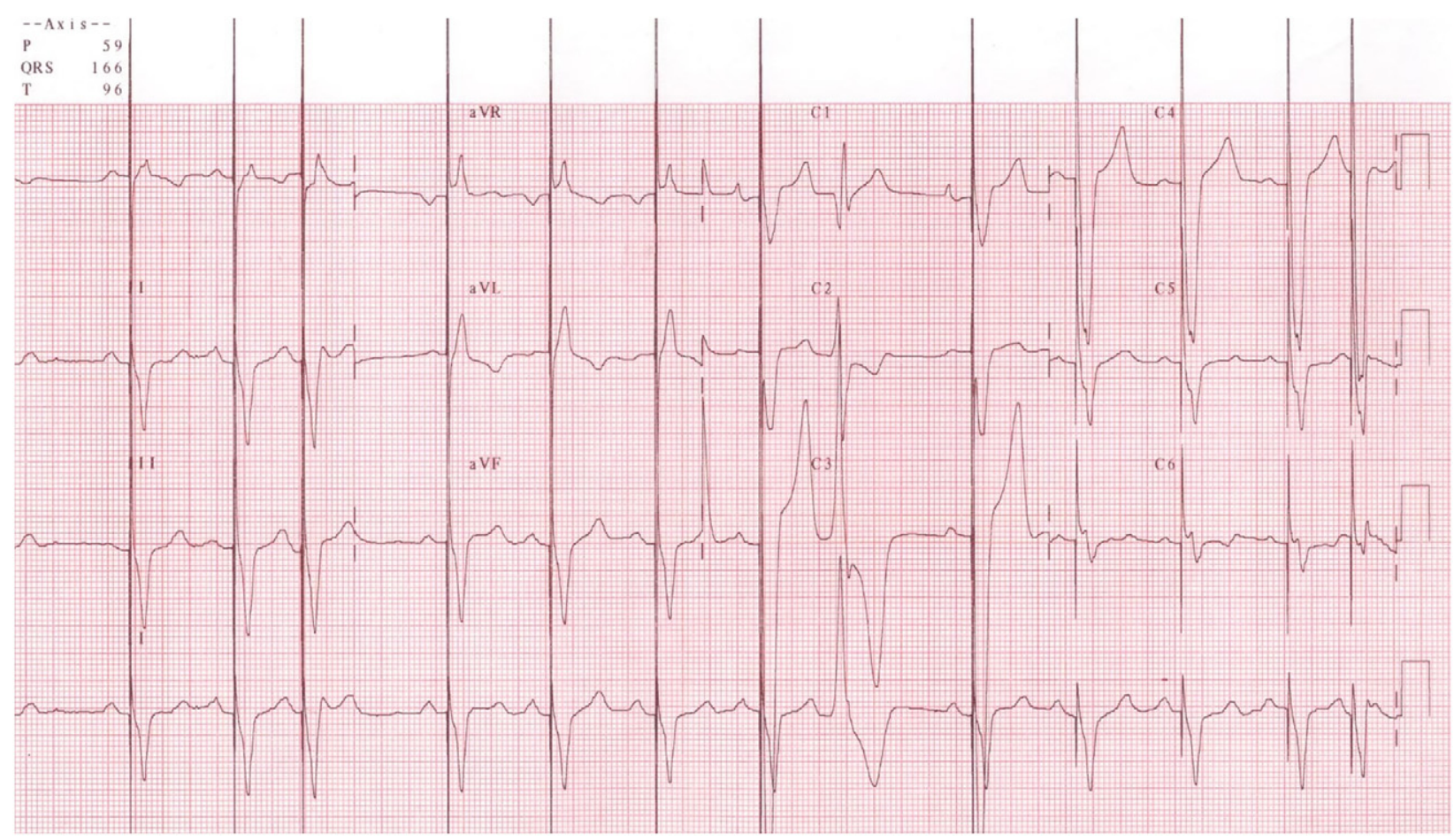

Fig. 1. Electrocardiogram revealed exaggerated pacemaker spikes in all leads and left bundle branch block with sinusal $\mathrm{p}$ wave.

(28\%), high thresholds (21\%), and late dislodgement (14\%). ${ }^{3}$ Lead insulation defects causing sensing abnormalities and extracardiac stimulation. Depending on the location of the defect, lead repair or lead replacement should be consider.

Twiddler syndrome can also a cause of pacemaker-induced extracardiac stimulation. It is defined as generator rotation with lead twisting and secondary malfunction of the leads. It is a rare but potentially lethal complication of pacemaker treatment. The predisposing factors include the creation of a large subcutaneous pocket, obesity, unconscious repetitive movements of the left arm, manipulation of the pocket, or the adoption of repeated poor postural positions. ${ }^{4}$

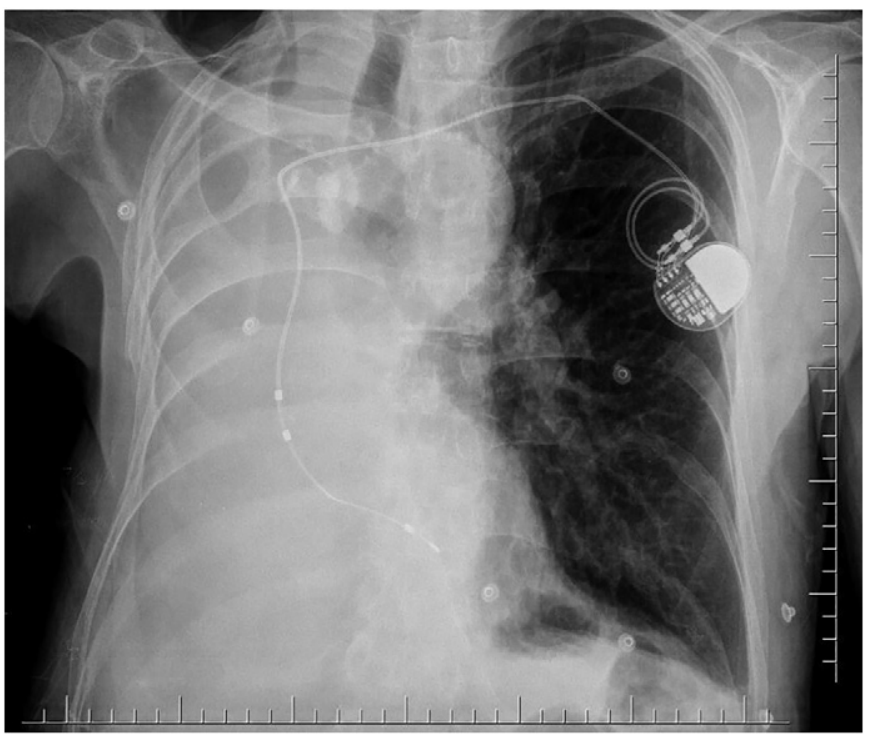

Fig. 2. Chest radiogram showing right pneumonectomy, single chamber permanent pacemaker with atrial sense part on the lead and the insulation defect around the subclavian region.
Lead dislodgement is most likely occured within hours or days of the implant with loss of capture. ${ }^{5}$ Pacemaker interrogation revealed an elevated pacing threshold with normal impedance. Fracture of the lead is a cause of persistent sound alarm from the pacemaker. Device interrogation is revealed loss of capture in the ventricular lead and a marked increase in its impedance. Chest radiogram shows the fracture of the lead. We reported a case of pacemaker induced pectoral muscle stimulation due to insulation defect and its management.

\section{Declaration of conflicting interests}

The authors declared no conflicts of interest with respect to the authorship and/or publication of this article.

\section{References}

1. Rasmussen IK, Pareek M. A video demonstration of pacemaker-induced pectoral muscle stimulation. BMJ Case Rep 2014;2014.

2. Radcliffe PJ, Jones S, Ward DE. An unusual cause of pacemaker current leakage causing muscle stimulation. Pacing Clin Electrophysiol Sep 1981;4(5):589-591.

3. Fortescue EB, Berul CI, Cecchin F, Walsh EP, Triedman JK, Alexander ME. Patient, procedural, and hardware factors associated with pacemaker lead failures in pediatrics and congenital heart disease. Heart Rhythm 2004;1(2):150-159.

4. Gonzalez Bermudez I, Pardo Fresno M, Garcia Campo E, Arnaiz Betolaza L, Crespo Carazo N, Beiras Torrado X. Twiddler syndrome as a cause of defibrillator malfunction. Rev Port Cardiol Dec 2012;31(12):837-838.

5. Bhattacharyya PJ, Agrawal S, Barkataky JC, Bhattacharyya AK. Medial subclavicular musculotendinous complex and insulation break: rare cause of late pacemaker lead malfunction. Indian Heart J Dec 2015;67(suppl 3):S89-S91. 